\title{
A Hybrid Force/displacement Performance-based Seismic Design Procedure for RC Frames
}

\author{
Soha Elkassas ${ }^{1}$, Ezzeldin Sayed-Ahmed ${ }^{2}$, Ezzat Fahmy ${ }^{3}$ \\ Department of Construction Engineering/ The American University in Cairo \\ New Cairo, 11835, Egypt \\ shkassas@aucegypt.edu; eysahmed@aucegypt.edu; ezzat@aucegypt.edu
}

\begin{abstract}
In this paper, the use of a recently proposed seismic design method called Hybrid force/displacement design is evaluated as an option for preliminary design of RC frames in the context of the latest framework for performance-based seismic design. A prototype $\mathrm{RC}$ frame is chosen as a design case study and is designed twice: using the traditional code method which is force-based and using the modified design procedure. The two designs are compared based on the number of iterations required, and the expected performance in reference to the results of nonlinear time-history analysis as the closest approximation of actual behaviour. It is concluded that the modified Hybrid method has higher efficiency and reliability in achieving targeted performance of RC frames, and thus is suitable for application in performance-based seismic design.
\end{abstract}

Keywords: Seismic design, RC frames, Performance-based design, Drift, Hybrid force-displacement design.

\section{Introduction}

Performance-based seismic design (PBSD) is a design philosophy in which the input criteria are reliably defined in terms of performance targets at various levels of seismic hazard. The term "performance" refers to the structure's ability to fulfill its intended purpose and stakeholders' targets pertaining to its functionality, safety or costs. In structural terms, performance is generally used to describe levels of damage.

The future of seismic design guidelines with respect to performance-based application was first fully described in the FEMA-445 report titled "Next-generation performance-based seismic design guidelines", published by the Federal Emergency Management Agency (FEMA) of the United States [1]. The document presented a program plan for establishing a comprehensive approach for performance-based design that converts probabilities of exceeding values of performance metrics to real-world losses such as casualties, time lost without operation, repair and replacement costs. The procedure proposed is illustrated in Fig. 1. It starts with a description of the selected performance objectives that form the input design criteria for performing a preliminary design, then the design performance is assessed and evaluated in terms of achieving the predefined objectives, and the process is repeated iteratively till the desired design objectives are satisfied. The methodology for the third step to assess performance has been subsequently established in the P-58 report [2] in a joint project with the Applied Technology Council, where it proposes a probability-based approach to characterize performance, and accordingly some standards were published for performance-based assessment and evaluation of existing structures like ASCE 41-13 [3]. Whereas progress in developing a practical design method to be used in the preliminary building design stage has been slow because of the complexity of inverting the relation between the design variables and performance measures.

As noted in the FEMA-445 report [1], a verdict on the success of the next-generation performance-based framework remains open unless guidelines are established for efficient preliminary building designs that are capable of closely providing the necessary performance. Development of such design approaches represents the most challenging phase of the project, where they need to be simple to understand and apply, relatively non-iterative to avoid the repetition of the lengthy performance assessment stage and at the same time should be able to satisfy several performance objectives.

In the context of the emerging performance-based methodology, there exists two options for preliminary design; either the force-based design (FBD) method which is the basis of most building code provisions and uses forces that are equivalent to the earthquake loading as the design input, or the displacement-based design (DBD) method which, as the name implies, uses displacement parameters as the starting point of design. These latter methods are better at controlling damage and performance of structures, because they impose restrictions on deformations from the beginning. However they lack practicality and acceptance in the design community when compared to conventional FBD methods due to the use of the 
nonfamiliar displacement response spectrum [4].The two most common DBD methods are the displacement coefficient method and the equivalent-linearization method, which use a substitute inelastic or a highly damped elastic singledegree-of-freedom (SDOF) systems respectively, to calculate the mechanical properties using a pushover curve [5]. These methods have an additional disadvantage of requiring a designed structure for adopting the SDOF representation for analysis, and thus they cannot be used for the design of new structures and are limited to the assessment and evaluation of the seismic performance of already existing structures.

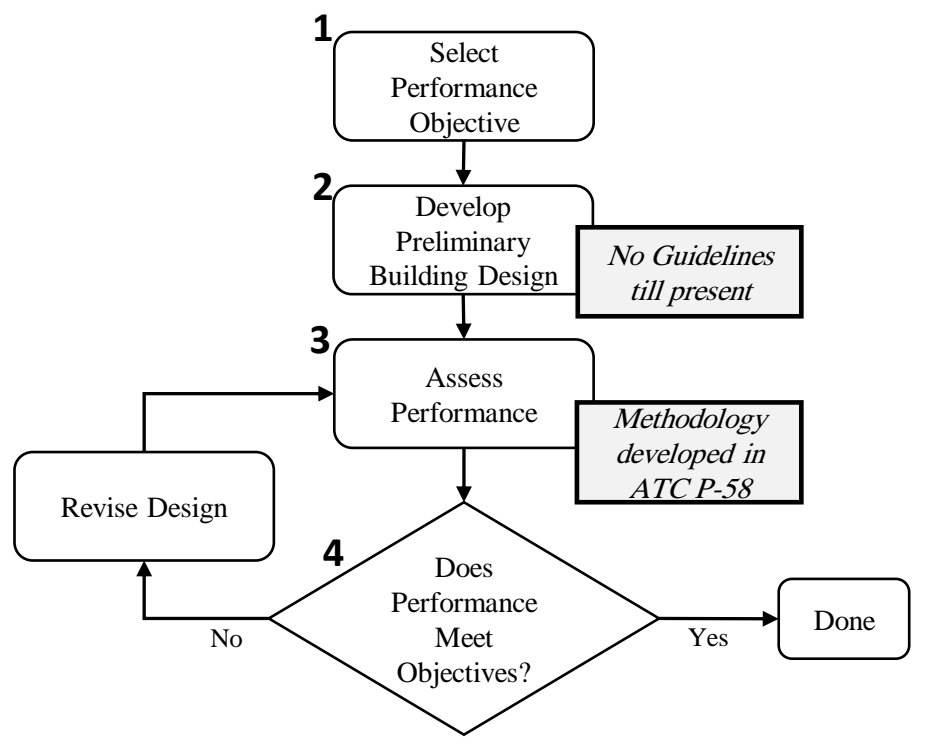

Fig. 1: Performance-based design approach, after FEMA-445 [1].

To combine the advantages of the FBD and DBD methods while still conforming to practical design formats and additionally minimize iterations, a group of researchers have proposed a "hybrid force/displacement based design" (HFDD) for design of steel frames and have developed the method over the past 15 years specifically for performancebased engineering applications [6-10]. The core idea of this methodology is that it starts by transforming target values of the inter-storey drift ratio (IDR), as an indicator of non-structural damage, to a target roof displacement, and then calculates the appropriate force reduction factor (FRF) required for limiting ductility demands to those of the estimated target roof displacement ductility. The drift design criteria are repeatedly defined as associated with three basic performance levels, and in this way, the design ensures control of both strength and drift performance for several seismic events. In addition to the benefit of using drift and ductility demands as input variables for initiation of the design process, the hybrid force/displacement approach has the major advantage of avoiding the use of a substitute SDOF system used in DBD while retaining the use of conventional elastic response spectrum analysis and design in line with current seismic codes. Recent comparisons between FBD, DBD and HFDD for the design of various types of steel structures proves the superiority of the HFDD method over other design methods in terms of achieving pre-selected performance targets [11]-[14]. An initiative to utilize the same procedure for composite steel/concrete structures was also proven successful [15]. The HFDD method was just newly adapted to RC structures [16] where Pian and his coresearchers have developed formulations for its application to RC structures based on numerical analyses of differentheight framed structures. They employed phenomenological models (lumped plasticity) to represent the nonlinear behaviour of reinforced concrete. Along the same frontier, the authors of this paper have extended the use of the HFDD to RC framed structures using an improved modelling technique of distributed plasticity to represent inelasticity along members cross sections and lengths [17]. The used fiber-modeling technique, despite being much more computationally demanding, is deemed more accurate in accounting for the complex hysteretic behaviour of reinforced concrete elements. The objective of this paper is to evaluate the efficiency and the reliability of this modified HFDD design method of RC structures. A typical example frame is analysed, and two versions of its design are compared: one using the traditional FBD method and the other employing the proposed HFDD method. 


\section{The Modified Hybrid Design Method}

\section{1. Procedure}

The HFDD method is merely a variation of the FBD where the FRF are calculated (rather than prescribed) based on a performance metric so that damage and performance can be incorporated in the initial design stage. Fig. 2 depicts the current method of seismic design as compared to the adjustment in the HFDD method. As shown in the diagram the modification shifts the incorporation of performance-based criteria to the beginning of the seismic-design process. Initial estimates for the structure's yield displacement is obtained by first designing the structure assuming elastic behavior under the frequently occurring earthquake, following the guidelines of the HFDD method developed for steel frames [13]. Then, the maximum roof displacement is estimated based on the structures' geometrical attributes and the preselected performance levels. While most codes define the FRF as the ratio of the elastic seismic forces with 5\% viscous damping to the minimum forces used in design [18-20], this definition is originally based on the conventional equal displacement rule [21] that states that displacement of an elastic and inelastic system are equal. Therefore, in the proposed method, the FRF is calculated based on the global displacement parameters by dividing the estimated maximum roof displacement at the desired seismic event by the design level displacements at the frequently occurring earthquake as an approximation of the global yield displacement. An equation for prediction of the maximum roof displacement was developed by the authors [17] for RC structures.

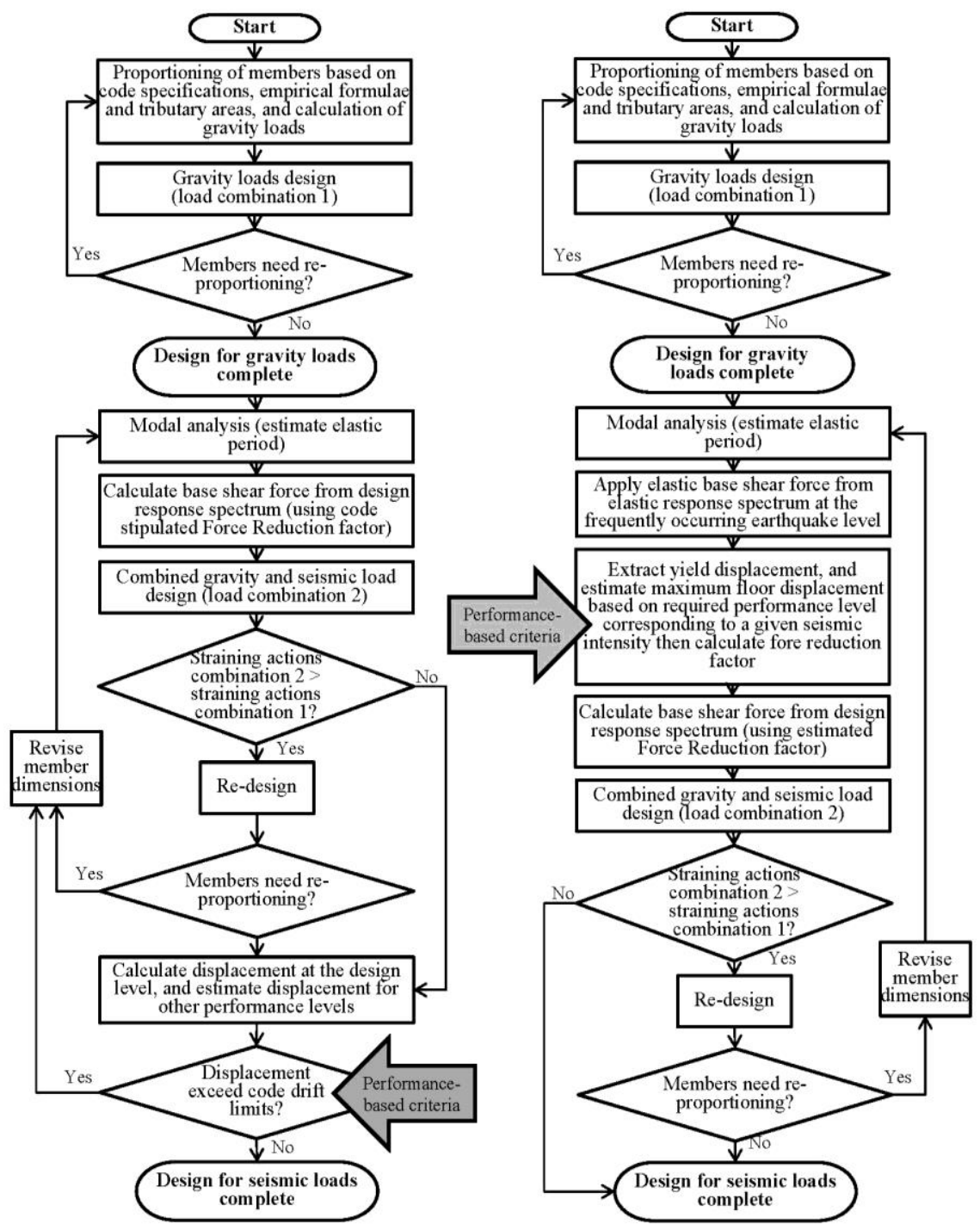

Fig. 2: Flowchart for the current seismic design method (left) versus the proposed modification (right). 


\section{2. Limitations}

Based on the models used for development of the maximum roof displacement estimate relations [17], the of the modified HFDD method is limited to regular frames with limited ductility and with number of stories 4 to 10 , number of bays 3 to 7 , and fundamental period ranging between $0.5 \mathrm{~s}$ and $1.3 \mathrm{~s}$. Its use cannot be extended to areas with different seismicity, soil and fault characteristics without further verification.

\section{Evaluation of the Hybrid Design Method}

The HFDD method is compared against the common code method and both compared to results of time history analysis as a close approximation of actual behaviour.

\section{1. Description of Building and Design Assumptions}

The building shown in Fig. 3 is selected for testing the modified design method. It has 8 floors and 3 bays and therefore lies in the range of applicability of the developed equations. The floor heights and the bay widths are equal to $3 \mathrm{~m}$ and $6 \mathrm{~m}$. The building is designed and detailed in accordance with the Egyptian design codes ECP- 203 [22] and ECP-201 [20], which are fundamentally in line with the regulations of EC8 [19], a typical modern seismic design code applicable to more than one country with different soil conditions, seismicity and construction practice.

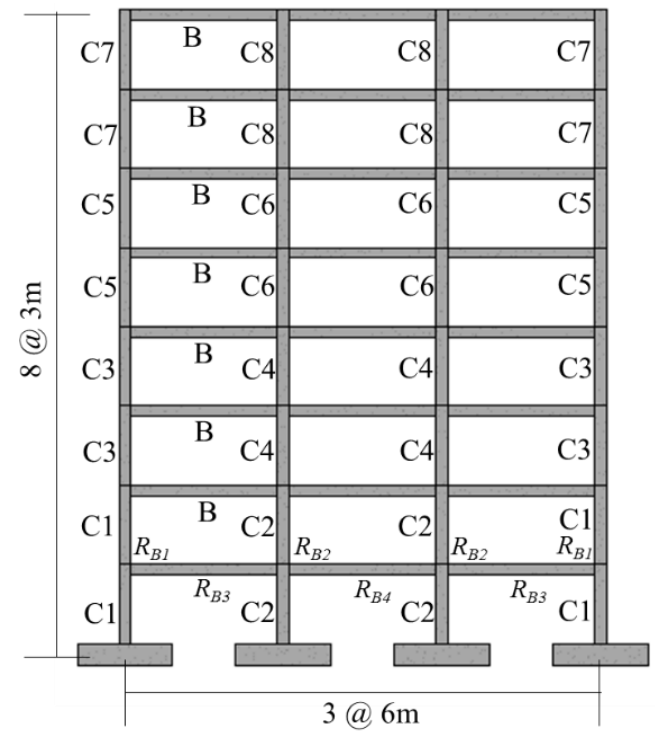

Fig. 3: Layout of the design example frame, together with the notation used for numbering the columns and beam reinforcement.

A characteristic concrete cube strength of $25 \mathrm{~N} / \mathrm{mm}^{2}$ and steel yield strength of $360 \mathrm{~N} / \mathrm{mm}^{2}$ are utilized. For gravity loading, the dead loads assumed include the self-weights of concrete elements and typical floor finishing of $1.5 \mathrm{kN} / \mathrm{m}^{2}$. A live load of $2.0 \mathrm{kN} / \mathrm{m}^{2}$ is also considered. The lateral load resisting system is chosen as a moment-resisting frame, and acceleration elastic response spectrum Type 1 is adopted as per ECP-201 [20], known as Type 2 in EC8 [19], for a "Soil Class C" which is dense or medium-dense sand. Limited ductility designs are developed corresponding to the norm of reinforcement detailing practice in many countries with low-to-moderate seismicity, and accordingly, a FRF with a value of 5 is used in design. Earthquake loading with a peak ground acceleration (PGA) of $0.35 \mathrm{~g}$ is assumed. The building's members are proportioned according to the straining actions from the gravity load combinations, then the two seismic design models are developed. The frame designed using the Code-stipulated R factors is referred to as the "Baseline frame (BL-frame)." While the frame designed using the proposed hybrid force/displacement method (employing the developed displacement relations for estimating a performance-related R factor) is given the name "Modified-design frame (MD-frame)." 


\section{2. Performance Levels}

The BL-frame is designed for the ultimate limit state for which the Code provides the elastic design response spectrum, and which corresponds to an earthquake with probability of exceedance of $10 \%$ in 50 years ( 475 years return period), referred to as the design-basis earthquake (DBE). The damage limitation state is checked as a post-design step, by conversion of the response values to correspond to the more frequent earthquake (FOE) with probability of exceedance of $50 \%$ in 50 years $(72$ years return period).

For the case of the MD-frame, the same performance levels are used in order to have a common basis of comparison, which are the Life-safety (LS) performance level and the Immediate Occupancy (IO) performance level, equivalent to the ultimate limitation state and the damage limitation state, respectively. Furthermore, one more performance level is specified to be able to evaluate the ability of the proposed modification in mapping the traditional design procedure to the multiperformance-based design framework, which is the Collapse Prevention (CP) performance level. Design performance objectives are developed by linking each performance level to a specified earthquake level and a limiting value of IDR, as summarized in Table 1. Those limiting criteria are based on the guidelines of FEMA-356 [23]. The same spectral shape is assumed for all the seismic action levels, adopting a single multiplicative factor which reflect regional seismotectonic environment, as shown in Fig. 4. It is assumed that the peak ground acceleration corresponding to the FOE equals one third of that of the DBE, i.e, $\mathrm{PGA}_{\mathrm{FOE}}=0.3 \times \mathrm{PGA} \mathrm{DBE}$, while the peak ground acceleration for the maximum considered earthquake (MCE) equals one-and-a-half that of the DBE i.e. $\mathrm{PGA}_{\mathrm{MCE}}=1.5 \times \mathrm{PGA}_{\mathrm{DBE}}$.

Table 1: Definition of the performance levels used in the design case study.

\begin{tabular}{|l|l|c|}
\hline Performance Level & \multicolumn{1}{|c|}{ Earthquake Intensity } & IDR limit \\
\hline \hline Immediate Occupancy (IO) & FOE with 50\% probability of occurrence in 50 years (72 years return period) & 0.1 \\
\hline Life Safety (LS) & DBE with 10\% probability of occurrence in 50 years (475 years return period) & 0.2 \\
\hline Collapse Prevention (CP) & MCE with 2\% probability of occurrence in 50 years (2475 years return period) & 0.3 \\
\hline
\end{tabular}

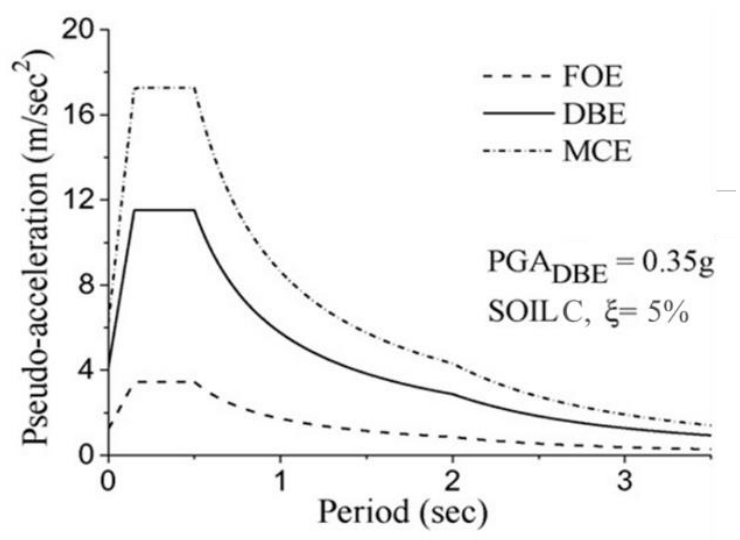

Fig. 4: Elastic Pseudo-acceleration design spectrum associated with the three study performance levels.

\section{3. Comparison between Code Design and Modified Design \\ 3. 3. 1. Efficiency and Iterations}

In order to compare the efficiency of the proposed modified HFDD design method to the Code design, the steps and results of the design of the BL-frame and MD-frame are presented. In both designs, all columns have square dimensions and the same beam is used in all floors for simplification. The columns' and beams' stiffness are reduced by $30 \%$ and $50 \%$ respectively, in order to account for cracking. And the mass source includes the gravity loads with 50\% of the live load. The following summarizes the steps and results of each design method. 


\section{3. 2. Baseline (BL) frame}

1. According to the requirements of the ECP-201 code [20], the design seismic action for the ultimate limit state at the DBE are determined and applied to the BL-frame model. It is calculated using the elastic response spectrum for $\mathrm{a}_{\mathrm{g}}=0.35 \mathrm{~g}$ reduced by a force-reduction factor (R) equals to 5 as prescribed for moment-resisting frames of limited ductility.

2. The resulting straining actions are used to determine the minimum required cross-sections and reinforcement ratios based on the strength and capacity design rules. Results are summarized in Table 2 (left-most columns).

3. The designed frame is checked for deformation (second design step) for the damage limitation state at the FOE. The code uses a factor, $v$, to convert the displacement response resulting from design at the DBE to its corresponding value at the FOE. This factor is specified as 0.4 for ordinary buildings. In order to convert the displacement values from the elastic design to its inelastic counterpart, the code uses a displacement amplification factor equals to 0.7R. Therefore, the IDR at the DBE (IDR $\mathrm{DBE}_{\text {) }}$ is calculated, using the IDR output from analysis as $\operatorname{IDR}_{\mathrm{DBE}}=0.7 \mathrm{R} \mathrm{IDR}_{\text {analysis }}=0.7 \mathrm{x} 5 \mathrm{x}$ $0.0074=0.026$. The corresponding IDR at the FOE, $\mathrm{IDR}_{\mathrm{FOE}}=v \times \mathrm{IDR}_{\mathrm{DBE}}=0.4 \times 0.026=0.011$, which is greater than the code-specified limit of $1 \%$ for damage limitation, therefore, design iteration is required.

4. Several iterations of changing member dimensions are performed, based on trial and error, until the IDR FOE satisfies the limit of $1 \%$ for the damage limitation state. The designed BL-frame member dimensions and reinforcement are also presented in Table 2 (middle columns). The designed BL-frame maximum values of IDR (at the FOE) is calculated to be $0.98 \%$ which satisfy the limit values of IDR for the damage limitation state. The expected maximum roof displacement is also found to be $0.45 \mathrm{~m}(0.7 \mathrm{R} \times 0.1287 \mathrm{~m})$.

Table 2: Member dimensions and reinforcement for all stages of code design and modified design method.

\begin{tabular}{|c|c|c|c|c|c|c|}
\hline \multirow{3}{*}{ Member } & \multicolumn{4}{|c|}{ Baseline-frame } & \multirow{2}{*}{\multicolumn{2}{|c|}{$\frac{\text { Modified design-frame }}{\text { One-step design }}$}} \\
\hline & \multicolumn{2}{|c|}{$\begin{array}{l}\text { For strength design step } \\
\text { only }\end{array}$} & \multicolumn{2}{|c|}{ Final after all iterations } & & \\
\hline & $\begin{array}{l}\text { Dimension } \\
(\mathrm{mm})\end{array}$ & Reinf. ratio (\%) & $\begin{array}{l}\text { Dimension } \\
(\mathrm{mm})\end{array}$ & Reinf. ratio (\%) & \begin{tabular}{|l|}
$\begin{array}{l}\text { Dimension } \\
(\mathrm{mm})\end{array}$ \\
\end{tabular} & Reinf.ratio (\%) \\
\hline $\mathrm{C} 1$ & 400 & 1.90 & 450 & 1.01 & 450 & 0.8 \\
\hline $\mathrm{C} 2$ & 450 & 1.94 & 450 & 1.01 & 450 & 0.8 \\
\hline $\mathrm{C} 3$ & 400 & 0.85 & 450 & 0.85 & 400 & 0.85 \\
\hline $\mathrm{C} 4$ & 400 & 1.90 & 400 & 1.90 & 450 & 0.8 \\
\hline $\mathrm{C} 5$ & 400 & 1.90 & 400 & 0.85 & 400 & 0.85 \\
\hline C6 & 400 & 0.85 & 400 & 0.85 & 400 & 0.85 \\
\hline $\mathrm{C} 7$ & 300 & 2.18 & 300 & 1.4 & 300 & 1.6 \\
\hline $\mathrm{C} 8$ & 300 & 2.18 & 300 & 1.01 & 300 & 1.8 \\
\hline $\mathrm{B}-\mathrm{R}_{\mathrm{B} 1}$ & $200 \times 450$ & 1.05 & $200 \times 450$ & 1.05 & $200 \times 500$ & 0.94 \\
\hline $\mathrm{B}-\mathrm{R}_{\mathrm{B} 2}$ & $200 \times 450$ & 1.27 & $200 \times 450$ & 1.27 & $200 \times 500$ & 1.85 \\
\hline $\mathrm{B}-\mathrm{R}_{\mathrm{B} 3}$ & $200 \times 450$ & 2.1 & $200 \times 450$ & 2.1 & $200 \times 500$ & 2.7 \\
\hline $\mathrm{B}-\mathrm{R}_{\mathrm{B} 4}$ & $200 \times 450$ & 0.85 & $200 \times 450$ & 0.85 & $200 \times 500$ & 0.85 \\
\hline
\end{tabular}

\section{3. 3. Modified-design (MD) frame}

1. For the modified HFDD procedure, the design seismic action is still obtained from the elastic response spectrum described in ECP-201code [20] but using a FRF that is calculated based on the most critical performance level that governs the design. The first step involves estimating the maximum target roof displacement associated with each performance objective (for number of floors equals 8 , and number of bays equals 3 ) as shown in Table 3.

2. The global yield displacement is estimated by applying the seismic load corresponding to the FOE with $\mathrm{R}=1$. The elastic response spectrum with $\mathrm{a}_{\mathrm{g}}=0.105 \mathrm{~g}$, is applied corresponding to the PGAFOE. The resulting roof displacement $\left(\Delta_{\mathrm{r}, \mathrm{y}}\right)$ is found to be 0.075 and the maximum IDR 0.004084 , which is less than the limiting value of 0.01 for the IO level. 
3. Based on the results of Step 1 and Step 2, the force-reduction factors $\left(\mathrm{R}_{\mathrm{i}}\right)$ associated with each performance level (i), and their equivalent at the DBE are computed as presented in Table 3.

4. The most critical force reduction factor $\mathrm{R}_{\mathrm{cr}}$ is the smallest one, which corresponds to the $\mathrm{CP}$ performance level, and is equal to 3.6. This shows that the collapse prevention performance level governs the design.

5. Seismic loads are applied based on the elastic response spectrum with $\mathrm{a}_{\mathrm{g}}=0.35 \mathrm{~g}$ reduced with $\mathrm{R}=3.6$, and the building is designed accordingly. Resulting member dimensions and reinforcing ratios are given in Table 2 (right-most columns).

Table 3: Calculation of performance level-dependent force reduction factors (FRF).

\begin{tabular}{|c|c|c|c|c|}
\hline $\begin{array}{l}\text { Performance level } \\
\text { (i) }\end{array}$ & \multicolumn{1}{|c|}{ PGA $_{\mathbf{i}}$} & $\Delta_{\mathbf{r}, \mathbf{i}}(\mathbf{m})$ & $\boldsymbol{R}_{\boldsymbol{i}}=\frac{\boldsymbol{\Delta}_{\boldsymbol{r}, \boldsymbol{i}}}{\boldsymbol{\Delta}_{\boldsymbol{r}, \boldsymbol{y}}}$ & $\boldsymbol{R}_{\boldsymbol{D} \boldsymbol{B} \boldsymbol{E}}=\boldsymbol{R}_{\boldsymbol{i}} \boldsymbol{x} \frac{\boldsymbol{P G} \boldsymbol{A}_{\boldsymbol{D} \boldsymbol{B} \boldsymbol{E}}}{\boldsymbol{P G G}_{\boldsymbol{i}}}$ \\
\hline \hline $\mathrm{IO}$ & $\begin{array}{l}\mathrm{PGA}_{\mathrm{FOE}}=0.3 \mathrm{x} \quad \mathrm{PGA}_{\mathrm{DBE}}= \\
0.105 \mathrm{~g}\end{array}$ & 0.108 & 2.1 & 7 \\
\hline $\mathrm{LS}$ & $\mathrm{PGA}_{\mathrm{DBE}}=0.35 \mathrm{~g}$ & 0.286 & 3.8 & 3.8 \\
\hline $\mathrm{CP}$ & $\begin{array}{l}\mathrm{PGA}_{\mathrm{FOE}}=1.5 \mathrm{x} \quad \mathrm{PGA}_{\mathrm{DBE}}= \\
0.525 \mathrm{~g}\end{array}$ & 0.408 & 5.4 & 3.6 \\
\hline
\end{tabular}

Although in the modified design, there is no need to check the drift requirements since they are embedded in the initial design process; the code method of drift check is tested, and the resulting maximum IDR at the FOE is found to be 0.0068 $(0.68 \%)$, which satisfies the limiting values of $1 \%$. Therefore, the modified design is proven to be more efficient since it is performed in one step taking into account the strength and displacement demands simultaneously, unlike the Code method in which the second deformation check step may turn out highly iterative. Moreover, the proposed modification allows considering multiple performance levels, while identifying the performance objective that governs the design.

\section{i. Performance of the Designed Frames}

In order to evaluate the reliability of the MD-frame design as compared to BL-frame design in achieving the intended performance objectives, nonlinear time history analysis (THA) is employed to provide a benchmark solution that reflects the closest approximation of actual behaviour. THA is performed using a suite of artificial ground motion records. More information regarding the THA procedure and assumptions can be found in [17].

The roof displacement results from the THA at the limit of the LS performance level are post-processed for the BLframe and the MD-frame, and their average compared to those estimated by the respective design method. Table 4 presents the THA results. The average roof displacement for the MD-frame when the IDR reaches 0.02 is $0.255 \mathrm{~m}$. This value is very close to the value estimated by the proposed design method where it was found to be $0.286 \mathrm{~m}$ as shown in Table 3 . The modified design overestimates the roof displacement by only $12 \%$. While the roof displacement of the BL-frame can be calculated by multiplying the displacement analysis results by the displacement amplification factor of $0.7 \mathrm{R}$, thus amounting to $0.7 \times 5 \times 0.1287=0.45 \mathrm{~m}$, which is $71 \%$ higher than the THA result of $0.264 \mathrm{~m}$. Thus, the Code method excessively overestimates displacement response which can lead to cumbersome and unnecessary iterations, with no uniform indication of real performance.

Table 4: THA results for the roof displacement at IDR=2\%.

\begin{tabular}{|l|l|l|l|l|l|l|l|l|}
\hline & EQ1 & EQ2 & EQ3 & EQ4 & EQ5 & EQ6 & EQ7 & Average \\
\hline BL-frame & 0.277 & 0.267 & 0.255 & 0.295 & 0.220 & 0.285 & 0.246 & 0.264 \\
\hline MD-frame & 0.248 & 0.228 & 0.241 & 0.301 & 0.270 & 0.287 & 0.212 & 0.255 \\
\hline
\end{tabular}

\section{Conclusion}

The HFDD method is a direct seismic design method, which requires no performance evaluation after the strength design step because the nonlinear behavior and performance criteria are built into the design process from the start i.e. the drift check is automatically accounted for. Compared to force-based methods, it minimizes the design iterations and avoids the oversimplified constant values of the force reduction factor. While compared to displacement-based procedures, it eliminates 
the errors introduced by the substitute SDOF approximation, and maintains the elastic domain of analysis with the conventional representation of earthquake action in terms of the pseudo-acceleration spectrum. Therefore, the HFDD combines the advantages of both the force-based and displacement-based procedures.

By application of the HFDD to a case study RC framed structure, it is verified that the modified HFDD can identify the performance level which truly controls the design, and accordingly results in a structure with higher reliability in meeting the predefined performance levels. The use of the HFDD method lead to structures that meet predefined performance objectives in terms of target inter-story drift, without the need for iteration or explicit drift check. Also the displacement values resulting from the proposed method are very close to the values estimated by nonlinear THA, which represents the best approximation of actual behaviour. From the procedural viewpoint, the HFDD method is proven to be able to complete the design directly in one step by considering the strength and deformation demands at the same time, while the code forcebased method requires many iterations after the deformation check step to reach the final design. It is concluded that the HFDD method can be readily incorporated as a preliminary design method for RC frames in the context of the broader nextgeneration performance-based design framework, especially for zones of low-to-medium seismicity where the added complexity of more complicated design methods cannot be justified. These conclusions are confined to the site assumptions and properties of the frame models utilized in development of the displacement prediction equations [17] that are included in the modified HFDD method.

\section{Acknowledgements}

The Mid-America Earthquake Center and the National Science Foundation (Award Number EEC-9701785) are acknowledged for the use of the finite-element analysis platform ZeusNL. The authors would like to thank Engineer Jasmin Osama for assistance in reflecting the design office experience in evaluation of the design methods.

\section{References}

[1] Federal Emergency Management Agency (FEMA), "Next-Generation Performance-Based Seismic Design Guidelines: Program Plan for New and Existing Buildings," report FEMA-445, Washington, D. C., 2006.

[2] FEMA, P-58, "Next-generation Seismic Performance Assessment for Buildings, Vol. 1 - Methodology," report prepared by the Applied Technology Council (ATC) for the FEMA, Washington, D.C., 2012.

[3] ASCE/SEI Standard 41-13, "Seismic Evaluation and Retrofit of Existing Buildings," ASCE, Virginia, USA, 2014.

[4] S.L. Kramer, "Performance-based design in geotechnical earthquake engineering practice," Proceedings of the 5th international conference on earthquake geotechnical engineering, Santiago, Chile, 2011.

[5] FEMA-440, "Improvement of Nonlinear Static Seismic Analysis Procedures," report FEMA, Washington, DC, 2006.

[6] T. L. Karavasilis, N. Bazeos and D. E Beskos, "A hybrid Force/Displacement Seismic Design Method for Plane Steel Frames," Proceedings of 1st ECEES, Geneva, Switzerland, No. 1013, 2006.

[7] T. L. Karavasilis, N. Bazeos and D. E Beskos, "Estimation of Seismic Drift and Ductility Demands in Planar Regular X-Braced Steel Frames," J. of Earthquake Engineering and Structural Dynamics, vol. 36, pp. 2273-2289, 2007.

[8] T. L. Karavasilis, N. Bazeos and D. E Beskos, "Behavior Factor for Performance-Based Seismic Design of Plane Steel Moment Resisting Frames," J. of Earthquake Engineering, vol. 11, no. 4, pp. 531-559, 2007.

[9] T. L. Karavasilis, N. Bazeos and D. E Beskos, "Seismic Response of Plane Steel MRF with Setbacks: Estimation of Inelastic Deformation Demands," J. of Constructional Steel Research, vol. 64, no. 6, pp. 644-654, 2008.

[10] A.S. Tzimas, T. L. Karavasilis, N. Bazeos and D. E Beskos, "Extension of the hybrid force/displacement seismic design method to 3D steel moment-resisting frame buildings," Engineering Structures, vol. 147, pp 486-504, 2017.

[11] N. Bazeos, "Comparison of three seismic design methods for plane steel frames," J. of Soil Dynamics and Earthquake Engineering, vol. 29, pp. 553-562, 2009.

[12] T. L. Karavasilis, N. Bazeos and D. E Beskos, "A new Seismic Design Method for Steel Structures." Chapter 15. In: Fardis, M.N. (Ed). Advances in Performance-Based Earthquake Engineering, vol 13: Springer e-books. 2010.

[13] A.S. Tzimas, T. L. Karavasilis, N. Bazeos and D. E Beskos, "A Hybrid force/displacement seismic design method for steel building frames," Engineering Structures, vol. 56, pp 1452-1463, 2013.

[14] D. E Beskos, "A performance-based hybrid force-displacement seismic design method for steel, reinforced concrete and composite frames," in M. Papadrakakis, M. Fragiadakis (eds.), Proceedings of the $7^{\text {th }}$ ECCOMAS Conference, COMPDYN 2019, Crete, Greece, no. 19423, 2019. 
[15] K.A. Skalomenos, G.D. Hatzigeorgiou, D.E Beskos, "Application of the hybrid force/displacement (HFD) seismic design method to composite steel/concrete plane frames," J. of Constructional Steel Research, vol. 115, pp 179-190, 2015 .

[16] C. Pian, J. Qiana, E. V. Muhoa,, D. E. Beskos, "A hybrid force/displacement seismic design method for reinforced concrete moment resisting frames," J. of Soil Dynamics and Earthquake Engineering, vol. 129, pp 1-14, 2020.

[17] S. H. Elkassas, M. N. AbdelMooty, E. Y. Sayed-Ahmed, and E. H. Fahmy "A Method for performance-based seismic design of reinforced concrete frame buildings," in M. Papadrakakis, M. Fragiadakis (eds.), Proceedings of the $7^{\text {th }}$ ECCOMAS Conference, COMPDYN 2019, Crete, Greece, no. 20016, 2019.

[18] ASCE/SEI Standard 7-10, "Minimum Design Loads for Buildings and Other Structures,"ASCE, Reston, Virginia, 2010.

[19] EC8. EuroCode 8, "Design of Structures for Earthquake Resistance. Part 1: General rules, seismic actions and rules for buildings (EN 1998-1:2004)," CEN, Brussels, 1998

[20] ECP-201-2008, "The Egyptian Code of Practice no-201 for Design Loads for Construction Works," Research Center for Housing and Construction, Cairo, Egypt, 2012.

[21] N. Newmark. and W. Hall, "Earthquake spectra and design," Earthquake Eng. Research Institute, Berkley, Cal., 1982. [22] ECP - 203-2007, "The Egyptian Code of Practice no-203 for Design and Construction of Concrete Structures," Research Center for Housing and Construction, Cairo, Egypt, 2007.

[23] FEMA, Pre-standard and Commentary for the Seismic Rehabilitation of Buildings," Federal Emergency Management Agency, Report FEMA-356, Washington, D. C., 2000. 